\title{
Experimental Study on Series Operation of Sliding Vane Pump and Centrifugal Pump
}

\author{
Tao Li, Weiming Zhang, Ming Jiang, and Zhengyang Li \\ Department of Petroleum Supply Engineering, LEU, Chongqing 400016, China \\ Correspondence should be addressed to Tao Li; 1ltt_200_2000@163.com
}

Received 19 June 2013; Revised 3 September 2013; Accepted 4 September 2013

Academic Editor: Ryoichi Samuel Amano

Copyright ( 2013 Tao Li et al. This is an open access article distributed under the Creative Commons Attribution License, which permits unrestricted use, distribution, and reproduction in any medium, provided the original work is properly cited.

\begin{abstract}
A platform for sliding vane pump and centrifugal pump tests is installed to study the series operation of them under different characteristics of pipeline. Firstly, the sliding vane pump and the centrifugal pump work independently, and the performance is recorded. Then, the two types of pumps are combined together, with the sliding vane pump acting as the feeding pump. Comparison is made between the performance of the independently working pump and the performance of series operation pump. Results show that the system flow rate is determined by the sliding vane pump. In order to ensure the stability of the series operation pumping system, the energy consumption required by the pipeline under the system flow should be greater than the pressure energy centrifugal pump can generate. Otherwise, the centrifugal pump can not operate stably, with reflux, swirl, gas-liquid twophase flow in the runner and strong vibration and noise. The sliding vane pump can be in serial operation with the centrifugal pump under limited conditions.
\end{abstract}

\section{Introduction}

In china, some oil devices are equipped with sliding vane pumps (such as the fixed refueling vehicles), and some are equipped with centrifugal pumps (such as the delivery pumps in oil pipeline). In order to complete the mission of transporting oil for emergency, there is a strong demand for combining these equipments together under current equipment system, thus leading to the series operation of the two types of pumps.

However, the working principles of sliding vane pump and centrifugal pump are completely different. The former belongs to positive displacement pumps, while the latter belongs to dynamic pumps $[1,2]$. The series, parallel, and series-parallel operations of centrifugal pumps are widely used [3-5]. Relatively, there are rare reports and research literatures on the series operation of sliding vane pumps and the two types of pumps. According to the working performance of sliding vane pump, Daniel and Wordley [5] put forth the concept that it is not necessary to run pumps in series because a positive displacement pump will be selfcompensating for system pressure and will only move a specific number at a given rpm, besides there is no advantage to place positive displacement pumps in series when they are in close proximity to each other. Karassik and Messina [1] presented an idea on the issue of series operation of positive displacement pump and centrifugal pump that it would be most unusual to encounter a positive displacement pump feeding into the suction of a centrifugal pump because of the high pressure that could be imposed on the centrifugal pump suction and because of the amplification of flow pulsations resulting from interaction of the characteristics of the two pumps, which could be deleterious to both pumps, yet with no experimental verification.

In order to investigate the series operational properties of them and guide their application, an experimental platform is designed and installed [6]. Firstly, the independent working characteristics of two selected pumps are tested. Then, they are tested in series operation to study and analyze the characteristics and regularity of their series operation.

\section{Performance Tests of Sliding Vane Pump and Centrifugal Pump}

2.1. The Experimental Process and Equipments. The experimental process and equipments of the independent operation 


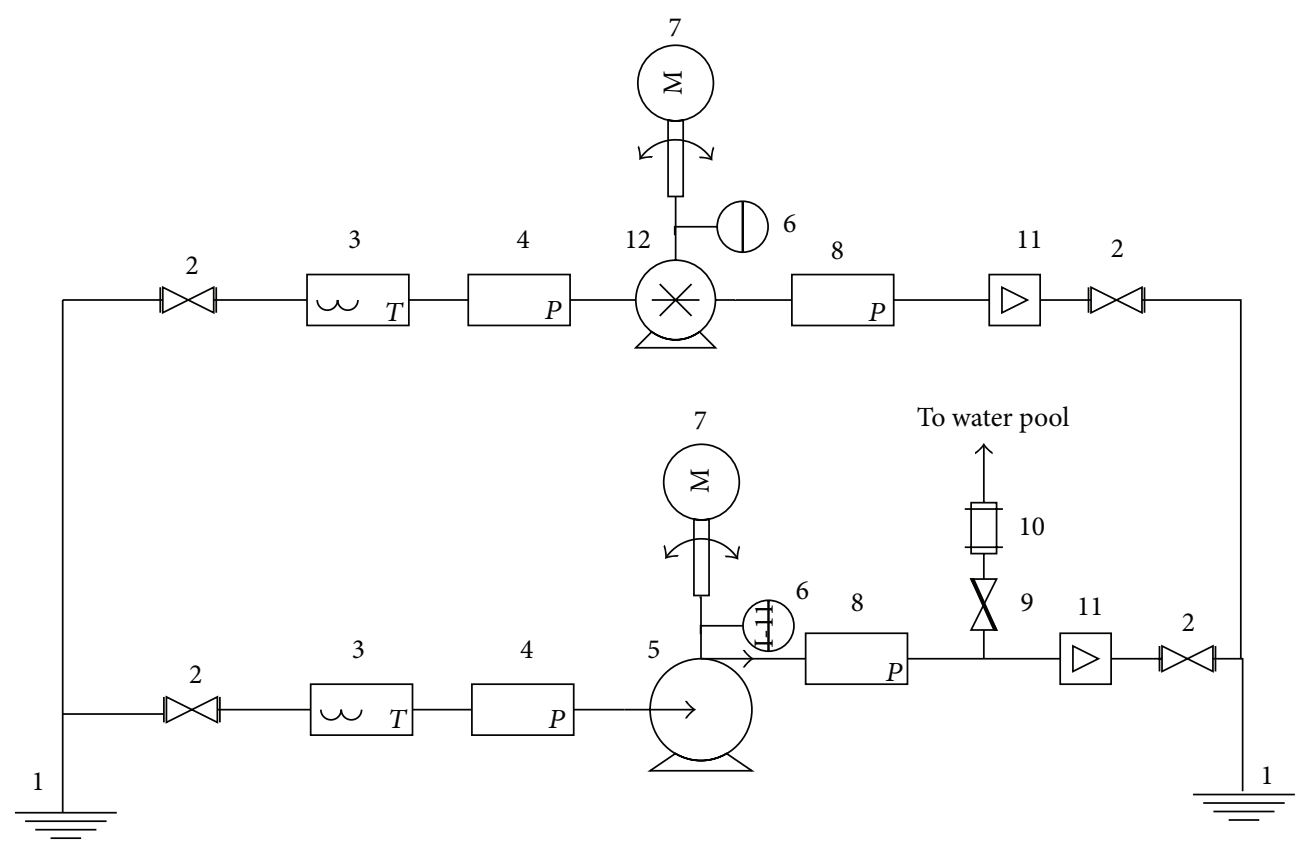
(1) Water pool
(7) Three-phase asynchronous motor
(2) Gate valve
(8) Pressure gauge
(3) Thermometer
(9) Butterfly valve
(4) Vacuum meter
(10) Sight glass
(5) Centrifugal pump
(11) Flow transmitter 1-2
(6) Transducer of torque and rotational speed
(12) Sliding vane pump

FIgURE 1: Flowchart of the independent operation of sliding vane pump and centrifugal pump.

TABLE 1: Parameters of pumps.

\begin{tabular}{lcccc}
\hline Model & Type & Differential pressure $(\mathrm{MPa})$ & Rated flow $\left(\mathrm{m}^{3} / \mathrm{h}\right)$ & Rotational speed $(\mathrm{r} / \mathrm{min})$ \\
\hline SUB50-15/40 & Sliding vane pump & 0.4 & 15 & 1440 \\
IH50-32-200 & Centrifugal pump & 0.5 & 12.5 & 2900 \\
\hline
\end{tabular}

of sliding vane pump and centrifugal pump are shown in Figure 1 and Table 1.

2.2. Drawing of Performance Curves. To take a sliding vane pump at a rotational speed of $1490 \mathrm{r} / \mathrm{min}$ and a centrifugal pump at $2940 \mathrm{r} / \mathrm{min}$, for example, through the parameters gained from the experimental records and calculation, the performance curves of two pumps are drawn (Figures 2 and 3 ). For the convenience of later comparative analysis, the differential pressure of centrifugal pump is used rather than the head capacity.

\section{Experiment on Series Operation of Sliding Vane Pump and Centrifugal Pump}

3.1. The Experimental Process. Based on the above single pump experiment, an experiment on the series operation of sliding vane pump and centrifugal pump is adapted, as shown in Figure 4. The pressure transmitter collects the pressure values on the inlet and outlet of sliding vane pump, the interposition of the series pipelines of two pumps, and the inlet and outlet of centrifugal pump, respectively, while flow transmitter collects the flow values of the outlet of these two pumps, respectively. The collected data are acquired and integrated on the DAQ board and recorded by a PC.

\subsection{The Experimental Methods and Steps}

3.2.1. Experiment I. (1) Shut down the by-pass butterfly valve, open all the gate valves in pipeline, start data collection at $0 \mathrm{~s}$, and start the sliding vane pump at $9 \mathrm{~s}$.

(2) After the system is running steadily, open centrifugal pump at $140 \mathrm{~s}$, and the two pumps operate in series. Shut down the centrifugal pump and sliding vane pump at $1012 \mathrm{~s}$ and $1046 \mathrm{~s}$ successively. Stop data collection at $1060 \mathrm{~s}$.

(3) Open the sliding vane pump and centrifugal pump again. When the two pumps operate in series, open the 


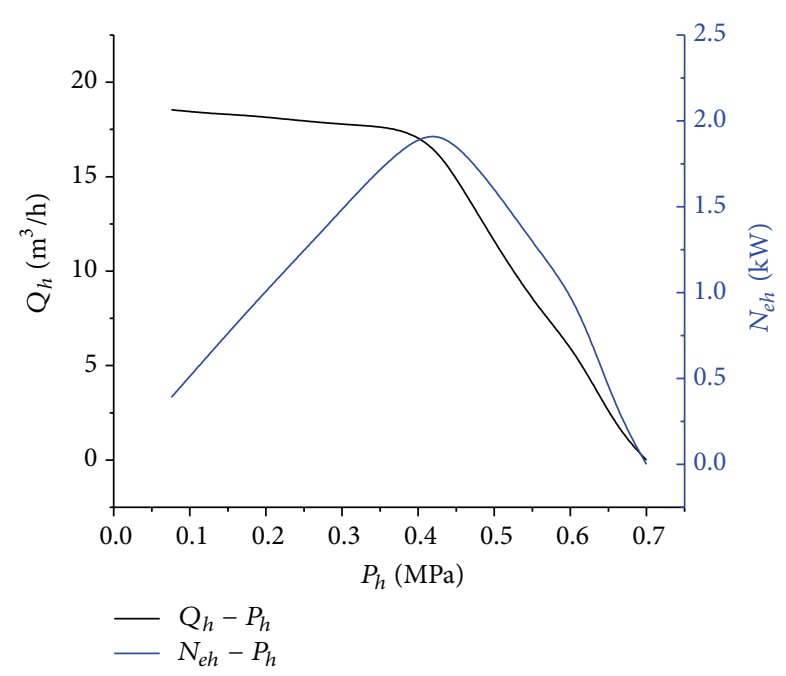

FIgURE 2: Performance curve of sliding vane pump.

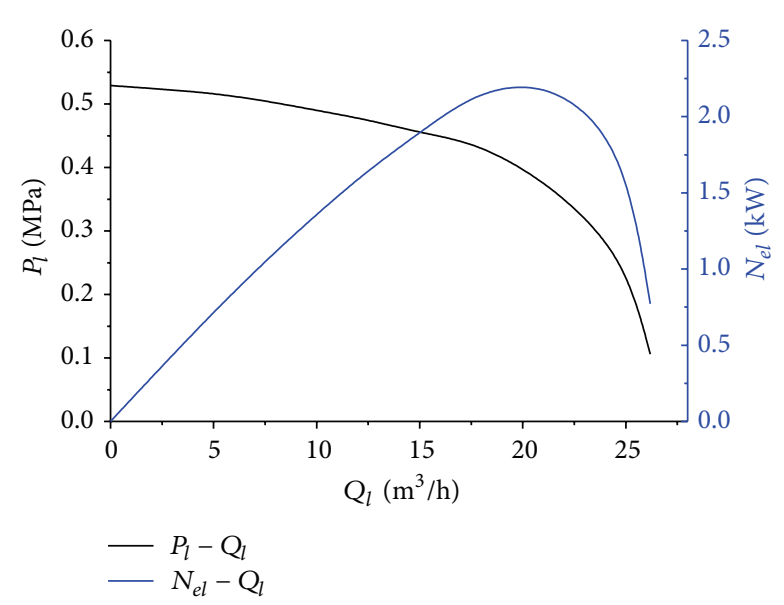

FIgURE 3: Performance curve of centrifugal pump.

butterfly valve of the by-pass pipeline on the outlet of centrifugal pump. Observe the liquid flow through sight glass.

\subsubsection{Experiment II. (1) It is the same as Step 1 in experiment} I.

(2) When the liquid flow is stable, start the centrifugal pump (at $98 \mathrm{~s}$ ). The two pumps then operate in series. When the pressure of centrifugal pump outlet is stabilized at $0.02 \mathrm{MPa}$, adjust valve 19 of centrifugal pump outlet (at $260 \mathrm{~s}$ ) to change the pipeline friction loss. Narrow down the opening of valve 19 to increase the outlet pressure of centrifugal pump by $0.05 \mathrm{MPa}$ each time until the valve is fully closed (1764s). The outlet pressures of centrifugal pump and its corresponding time are shown in Table 2.

(3) Open gate valve 19 quickly until it is fully opened, and stop the centrifugal pump and sliding vane pump, stop data collection.
TABLE 2: Outlet pressures of centrifugal pump versus time.

\begin{tabular}{lccccc}
\hline$T(\mathrm{~s})$ & $P_{l u}(\mathrm{MPa})$ & $t(\mathrm{~s})$ & $P_{l u}(\mathrm{MPa})$ & $t(\mathrm{~s})$ & $P_{l u}(\mathrm{MPa})$ \\
\hline 272 & 0.07 & 833 & 0.47 & 1345 & 0.87 \\
376 & 0.12 & 890 & 0.52 & 1408 & 0.92 \\
442 & 0.17 & 962 & 0.57 & 1460 & 0.97 \\
504 & 0.22 & 1023 & 0.62 & 1524 & 1.02 \\
582 & 0.27 & 1085 & 0.67 & 1590 & 1.07 \\
646 & 0.32 & 1148 & 0.72 & 1640 & 1.12 \\
702 & 0.37 & 1213 & 0.77 & 1705 & 1.17 \\
770 & 0.42 & 1285 & 0.82 & 1764 & 1.19 \\
\hline
\end{tabular}

Note: $P_{l u}$ is the outlet pressure of the centrifugal pump, which is $1.19 \mathrm{MPa}$ when the valve is fully closed.

\subsection{Results and Analysis}

3.3.1. Results and Analysis of Experiment I. In experiment I, the system is stable when the sliding vane pump is working alone. All parameters have good stability. But after the centrifugal pump is turned on, the centrifugal pump and its pipeline begin to vibrate and obvious noise and severe calorification can be observed. The changes of all parameters are shown in Figures 5 and 6. Then, it can be observed that a lot of bubbles flow out from the pipeline to sight glass in Step (3), which suggests that the liquid in centrifugal pump is being vaporized. So, there is a two-phase flow of liquid and gas within centrifugal pump and the pipeline behind it.

As shown in Figure 5, when sliding vane pump is turned on, $P_{h i}$ quickly falls to $-0.047 \mathrm{MPa}$, and $P_{h u}, P_{m}$, and $P_{l i}$ quickly rise to $0.264,0.256$, and $0.235 \mathrm{MPa}$. $P_{l u}$ rises to $0.02 \mathrm{MPa}$. At $140 \mathrm{~s}$, the centrifugal pump is opened. $P_{h i}$ slightly falls down while $P_{h u}, P_{m}$, and $P_{l i}$ significantly drop to $-0.049,-0.058$ and $-0.077 \mathrm{MPa}$. $P_{l u}$ slightly increases. In series operation, all pressures basically remain the same. At $1012 \mathrm{~s}$, shut down the centrifugal pump. All the parameters return to the independent working state of sliding vane pump. Shut down the sliding vane pump. All the parameters return to original state.

As shown in Figure 6, when sliding vane pump is opened, $P_{h}$ rises to $0.31 \mathrm{MPa}$ immediately. All the energy consumed is borne by sliding vane pump. At this moment, centrifugal pump is the leading energy consumption of system. The pressure drops to $0.22 \mathrm{MPa}$ after passing the centrifugal pump. $Q_{h}$ is the same as $Q_{l}$ at $17.7 \mathrm{~m}^{3} / \mathrm{h}$. At $140 \mathrm{~s}$, the centrifugal pump is opened. $P_{h}$ immediately reduces to $-0.002 \mathrm{MPa}$. $P_{l}$ increases to $0.1 \mathrm{MPa}$ rapidly, and the two exchange their roles as energy consumer and provider. $Q_{h}$ increases slightly to $18.5 \mathrm{~m}^{3} / \mathrm{h}$ under the fixed speed because of the declination of $P_{h}$. The value of $Q_{l}$ is bigger than $Q_{h}$. This is because the evaporation of liquids takes place after reaching the centrifugal pump. Within the fixed volume of pipeline, a large amount of gas reduces and compresses the volume of liquid, thus leading to the increase of the flow velocity which is proportional to the value of flow sensor. However, the pure liquid flow of system is $Q_{h} . P_{h}$ and $P_{l}$ basically remain the same during the series operation. 


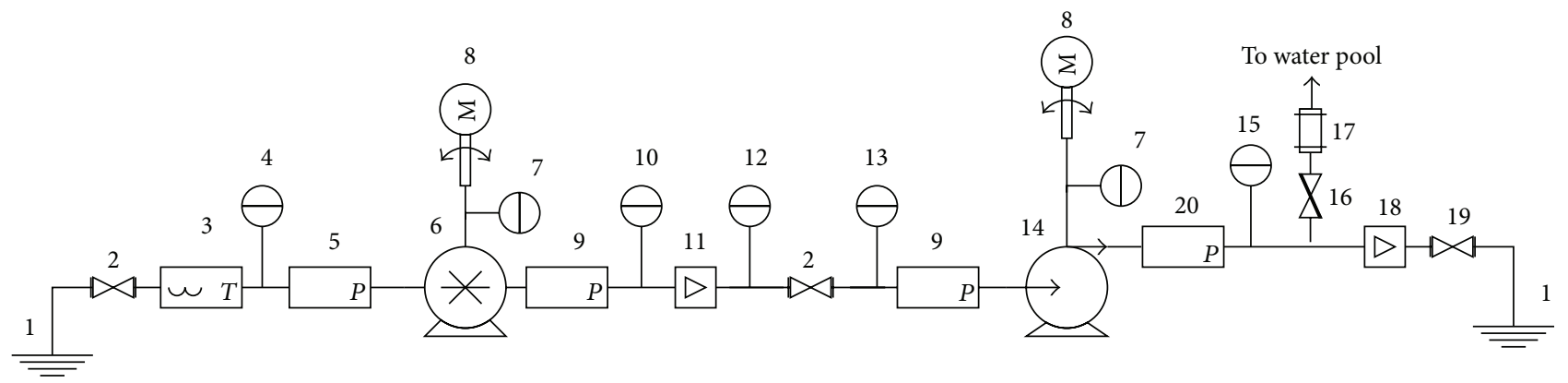
(1) Water pool
(9) Vacuum pressure gauge
(2) Gate valve
$(11,18)$ Flow transmitter 1-2
(3) Thermometer
(14) Centrifugal pump
$(4,10,12,13,15)$ Pressure transmitter 1-5
(16) Butterfly valve
(5) Vacuum meter
(17) Sight glass
(6) Sliding vane pump
(19) Gate valve
(7) Transducer of torque and rotational speed
(20) Pressure gauge
(8) Three-phase asynchronous motor

FIgURE 4: Series operation flowchart of sliding vane pump and centrifugal pump.

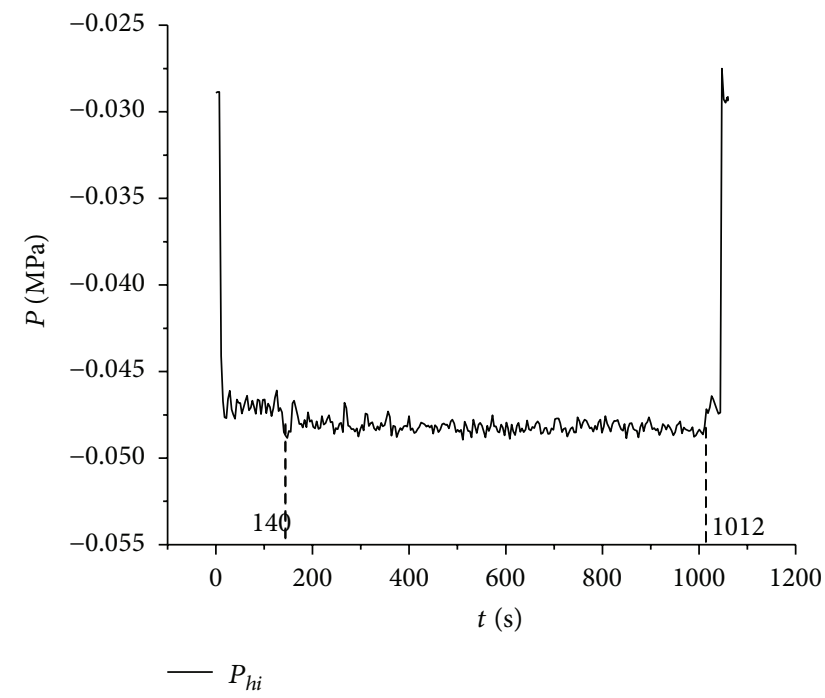

(a)

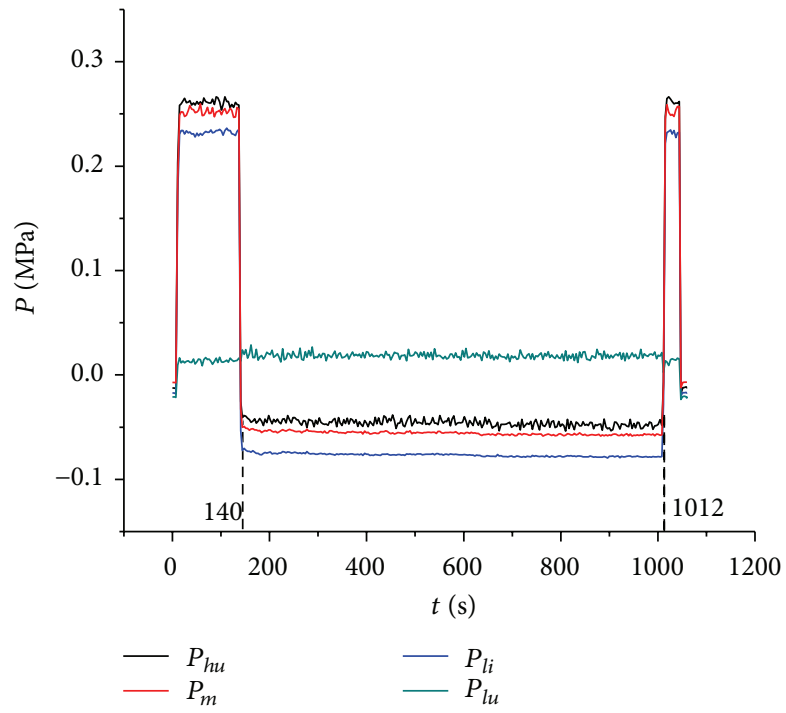

(b)

Figure 5: Variation trend of $P_{h i}, P_{h u}, P_{m}, P_{l i}$, and $P_{l u}$ in experiment I. $P_{h i}$-suction pressure of sliding vane pump, $P_{h u}$-discharge pressure of sliding vane pump, $P_{m}$-pressure at the interposition of the series pipelines of two pumps, $P_{l i}$-suction pressure of centrifugal pump, and $P_{l u}$-discharge pressure of centrifugal pump.

Compared with the independent working condition of the two pumps, the flow and differential pressure changes of the sliding vane pump follow the rule which is suggested in Figure 2 whether it works independently or operates in series with the centrifugal pump. However, the differential pressure of the serial centrifugal pump is only $0.1 \mathrm{MPa}$ when the flow is $18.5 \mathrm{~m}^{3} / \mathrm{h}$ which significantly deviates from the differential pressure $0.43 \mathrm{MPa}$ when centrifugal pump works independently under the same flow shown in Figure 3. The serial centrifugal pump receives the dual effect of both the sliding vane pump and the characteristics of the pipeline. The flow is determined by the preceding-stage sliding vane pump, and the differential pressure is influenced by the characteristics of the pipeline. The centrifugal pump itself can provide the energy amounting to $0.43 \mathrm{MPa}$ which is much bigger than that needed by the pipeline. Therefore, the complex and unstable flow will be resulted inside the centrifugal pump to offset the superfluous energy in order to maintain the balance between supplies and demands. The energy loss appears in the form of reflux and swirl $[7,8]$. 


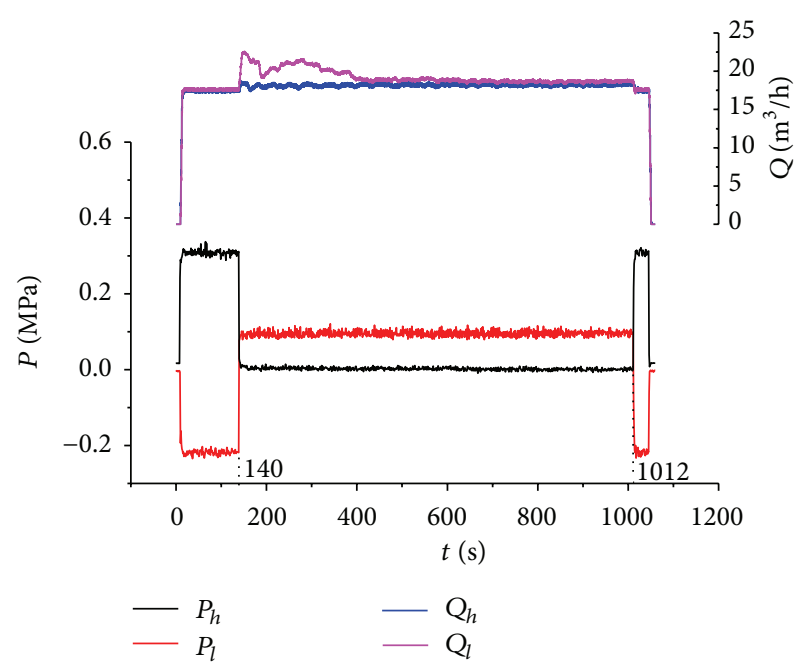

FIgURE 6: Variation trend of flow and differential pressure in experiment I. $P_{h}$-differential pressure of sliding vane pump, $P_{l}-$ differential pressure of centrifugal pump, $Q_{h}$ - outlet flow of sliding vane pump, and $Q_{l}$-outlet flow of centrifugal pump.

The stronger the reflux is, the bigger the volume of the swirl is and the greater the energy loss is. Moreover, it will lead to the pulsation of flow and pressure, which will further lead to vibration and noise. That is why there is vibration and noise in the experiment.

3.3.2. Results and Analysis of Experiment II. Based on experiment I, we close the outlet valve of the centrifugal pump gradually to make a further study in experiment II. The variation of the system parameters in the experiment is shown from Figures 7 to 8 .

The working status of the system before closing the outlet valve and after opening the outlet valve is the same as that in experiment I. So, emphases are put on the dynamic variation regularity of each parameter during the valve closing process in experiment II. The outlet valve of the centrifugal pump is closed gradually with $P_{l u}$ as reference standard. Figure 7 shows the periodic rise of $P_{l u}$ while the valve is closing. When the valve is completely closed, the pressure rises to its maximum value of $1.19 \mathrm{MPa}$. At the points of $0.17,0.22$, and $0.27, P_{l u}$ fluctuates greatly. From $260 \mathrm{~s}$ to $702 \mathrm{~s}$, the variation trends of $P_{h u}, P_{m}$, and $P_{l i}$ are consistent with each other and with little variation. Between $702 \mathrm{~s}$ and $1764 \mathrm{~s}, P_{h u}, P_{m}$, and $P_{l i}$ increase apparently and reach respective peak value at $1764 \mathrm{~s}$ when the liquid flows back completely through the safety valve.

$P_{h i}$ is stable at first and then begins to increase. The value remains basically unchanged from $260 \mathrm{~s}$ to $702 \mathrm{~s}$. From $702 \mathrm{~s}$ to $1285 \mathrm{~s}$, the increase is slow. From $1285 \mathrm{~s}$ to $1764 \mathrm{~s}$, the increase is significant. At $1764 \mathrm{~s}$, it reaches the peak of $-0.030 \mathrm{MPa}$.

Figure 8 is the variation trend of the flow and differential pressure in experiment II. The value of $Q_{l}$ is still greater than that of $Q_{h}$ during $98 \mathrm{~s}$ and $272 \mathrm{~s}$. After further turning down the valve, $Q_{l}$ and $Q_{h}$ gradually become consistent. The variation of parameters during valve closing process can be classified into three periods. Comparison is made between the performance in series operation and the performance in independent operation which is shown in Figures 9 and 10. In the first period (from $260 \mathrm{~s}$ to $702 \mathrm{~s}$ ), $P_{h}$ shows little change, staying at $-0.003 \mathrm{MPa}$. The stable working condition of the sliding vane pump enables $Q_{h}$ to maintain around $18.5 \mathrm{~m}^{3} / \mathrm{h}$, while $P_{l}$ keeps surging with the flow remaining unchanged, which reaches $0.43 \mathrm{MPa}$ at $702 \mathrm{~s}$. Besides, the working status of the centrifugal pump is quite unstable with the pressure ranging from $0.2 \mathrm{MPa}$ to $0.3 \mathrm{MPa}$. At this period, the differential pressure of the centrifugal pump is still less than that when it works independently under the same flow (Figure 10) which further validates its abnormal operation state. In addition, the fierce unsteady flow within the pump and pipe changes the velocity and pressure distribution of liquid in the runner. This remarkably reduces the efficiency, degrades the performance, and shortens the lifespan of the centrifugal pump. The change in the characteristics of the pipeline has no direct impact on the sliding vane pump. But the centrifugal pump makes a response and comes close to a stable working status. In the second period (from $702 \mathrm{~s}$ to $1285 \mathrm{~s}), P_{h}$ keeps rising and reaches the rated differential pressure of the safety valve of $0.4 \mathrm{MPa}$ at $1285 \mathrm{~s}$. The flow rate $Q_{h}$ reduces from $18.5 \mathrm{~m}^{3} / \mathrm{h}$ to $17.4 \mathrm{~m}^{3} / \mathrm{h}$ slowly. $P_{l}$ rises slowly from $0.43 \mathrm{MPa}$ to $0.44 \mathrm{MPa}$ due to the decrease of the system flow rate. At this period, in the case that the centrifugal pump works steadily and that the safety valve of the sliding vane pump does not open, the change in the characteristics of the pipeline exerts a major impact on the sliding vane pump. Therefore, the system flow rate has minor change. The centrifugal pump works steadily under the flow. In the third period (from $1285 \mathrm{~s}$ to $1764 \mathrm{~s}$ ), $P_{h}$ increases gently compared with the second period. The opening of the safety valve and the increasing $P_{h}$ cause the decrease of $Q_{h}$. The steady declining changes into ladder-formed declining, and at $1764 \mathrm{~s}$, it reduces to $0 \mathrm{~m}^{3} / \mathrm{h} . P_{l}$ rises because of the declining of $Q_{l}$, and the rising trend is more stable than the first period. We can see that once the sliding vane pump's safety valve opens, the change in the characteristics of the pipeline will result in great change in the working parameters of the two pumps as well as the flow.

3.4. Conclusions. Through the analysis and comparison of the results in experiment I and experiment II, the following conclusions can be drawn.

(1) The system flow rate is determined by the characteristics of the feeding sliding vane pump. The working performance of the two pumps and the characteristics of the pipeline are crucial for normal and steady system operation. In the serial use, the corresponding relation between the system flow and the differential pressure of the sliding vane pump fits its independent working characteristics well. The operation of the centrifugal pump effectively changes the differential pressure of the sliding vane pump by sharing the pressure energy of the system, thus leading to the change in the system flow. 


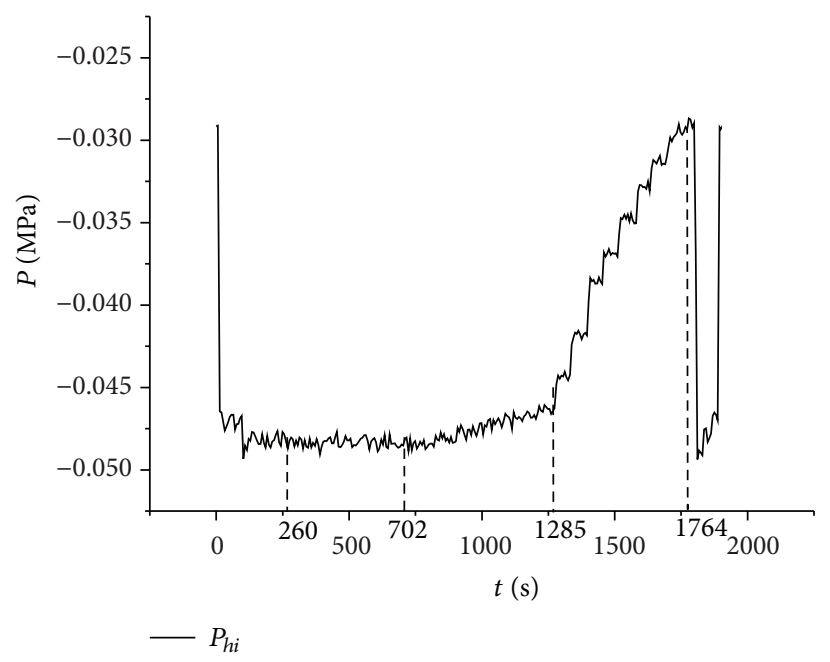

(a)

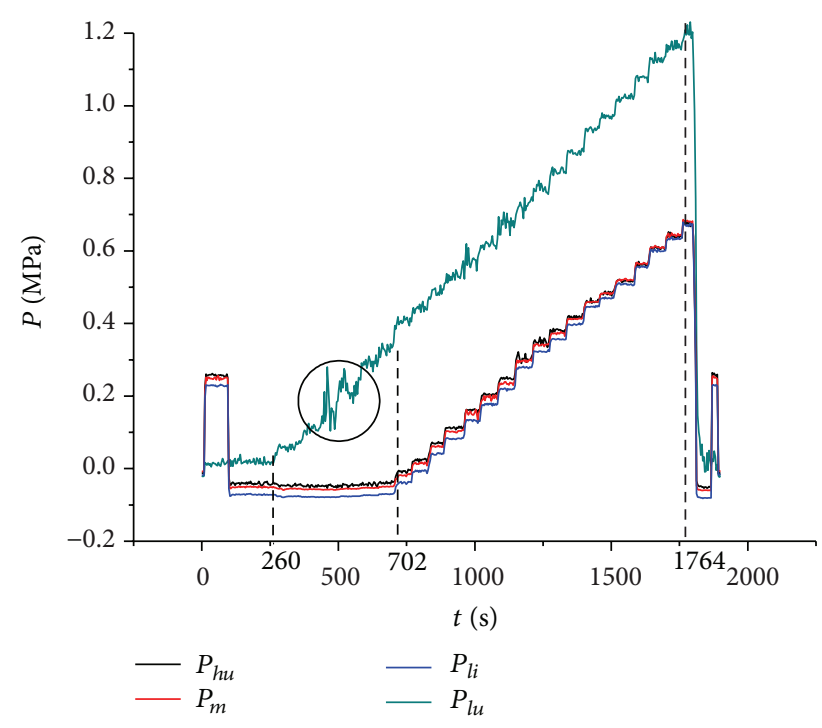

(b)

FIgURE 7: Variation trend of $P_{h i}, P_{h u}, P_{m}, P_{l i}$, and $P_{l u}$ in experiment II.

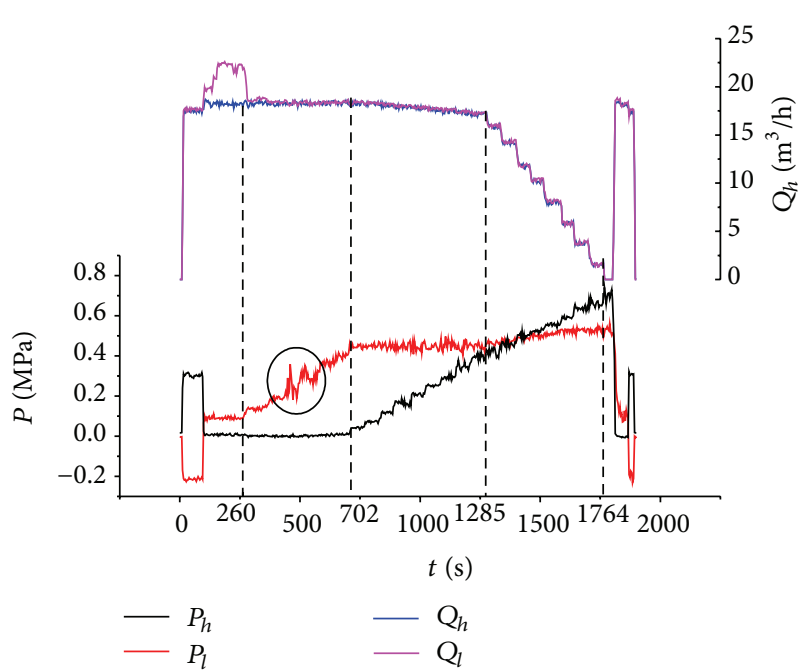

FIGURE 8: Variation trend of flow and differential pressure in experiment II.

(2) The centrifugal pump works under the flow determined by the sliding vane pump. If the energy it provides is larger than the energy consumed by flow, then fierce unsteady such as reflux, swirl, gas-liquid two-phase flow will occur inside the centrifugal pump to consume the superfluous energy.

(3) During different periods, the change of the pipeline characteristics has different impacts on the working status of the two pumps. When the centrifugal pump is under abnormal operation, changing the pipeline friction loss causes nearly no sliding vane performance variation and no flow rate change. The centrifugal pump changes the operation parameters and slowly comes near to or far away from the normal working status. After the centrifugal pump works

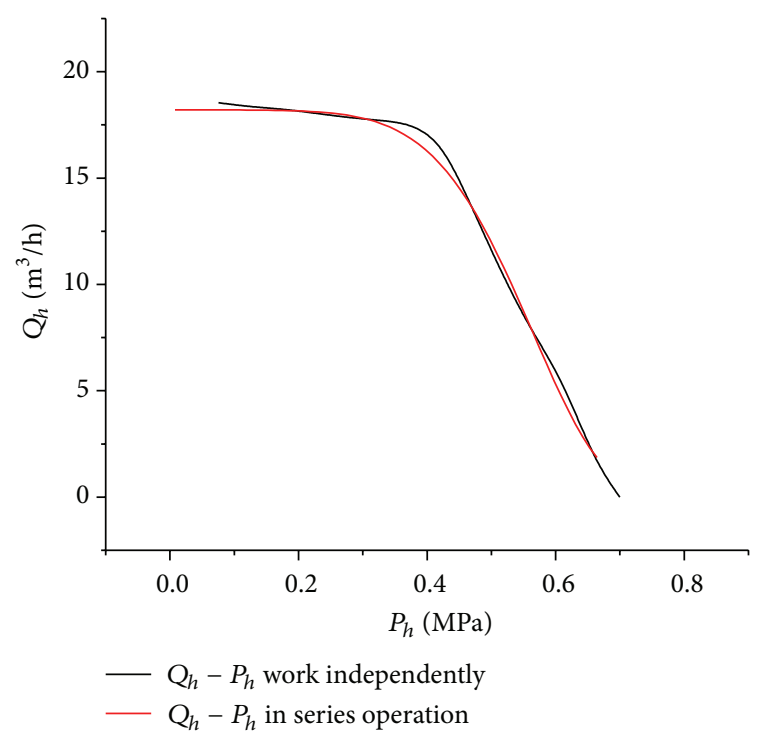

Figure 9: Comparison of performances of sliding vane pump.

steadily and before the safety valve opens, the change in the characteristics of the pipeline exerts a major influence on the operation of the sliding vane pump. As a consequence, the system flow has a small-scale change. After the safety valve opens, both of the two pumps change the operation parameters to adapt to the change in the characteristics of the pipeline.

\section{Summary}

Series operation experiments for sliding vane pump and centrifugal pump are conducted. Sliding vane pump is used as the preceding-stage pump and the centrifugal pump as 


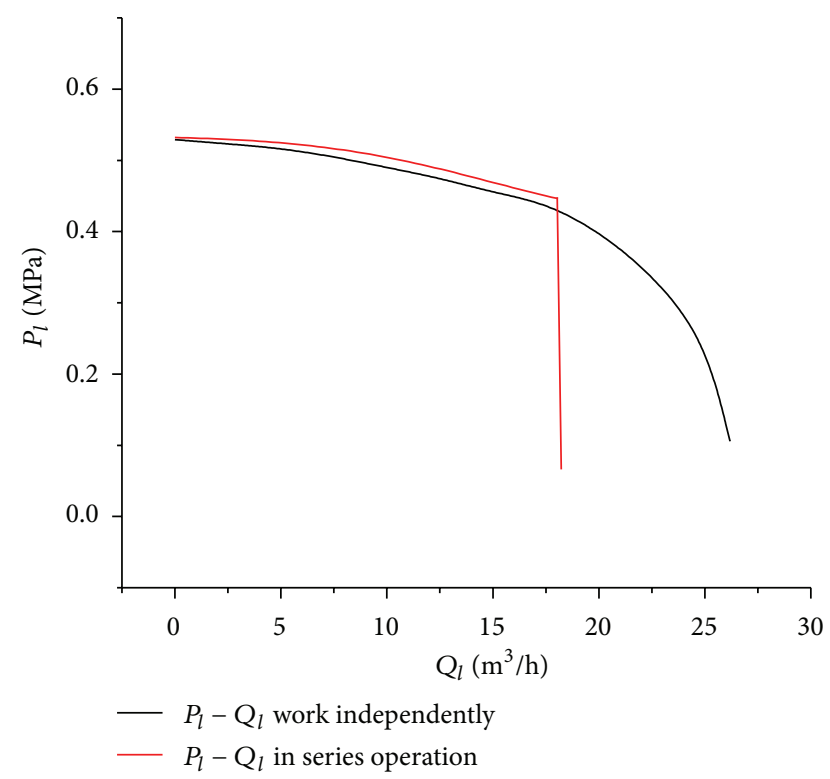

FIGURE 10: Comparison of performances of centrifugal pump.

the secondary pump. By changing the friction loss of the pipeline, results are gained under different operational conditions. Experimental results show that the system rate of flow is determined by the sliding vane pump. The centrifugal pump works under the flow rate restricted by the sliding vane pump. Only when the friction of the pipeline is greater than the pressure energy that the centrifugal pump can provide, the system can operate normally. Otherwise, the system will work unsteadily with calorification, vibration, and noise. So, the sliding vane pump can be in serial operation with the centrifugal pump under limited conditions.

\section{Acknowledgment}

This paper is supported by the Academic Innovation Fund of Logistical Engineering University.

\section{References}

[1] I. J. Karassik and J. P. Messina, Cooper Paul, and Heald C. C.Pump Handbook, McGraw-Hill, New York, NY, USA, 3rd edition, 2001.

[2] J. F. Gulich, Centrifugal Pumps, springer, New York, NY, USA, 2007.

[3] J. Yuan and S. Yuan, "Prediction of performance for dissimilar centrifugal pumps coupled in series or in parallel," Drainage and Irrigation Machinery, vol. 22, no. 6, pp. 1-4, 2004.

[4] E. da Costa Bortoni, R. A. Almeida, and A. N. C. Viana, "Optimization of parallel variable-speed-driven centrifugal pumps operation," Energy Efficiency, vol. 1, no. 3, pp. 167-173, 2008.

[5] U. C. Daniel and M. Wordley, "A comparison of the application of centrifugal and positive displacement pumps," in Proceedings of the 17th International Pump Users Symposium, pp. 145-152, 2005.
[6] C. Wu, J. Chen, and B. Chen, "Design and application of performance test bed for sliding-vane pump," Petrochemical Equipment, vol. 39, no. 1, pp. 14-16, 2010.

[7] S. Yuan, Y. Liang, J. Yuan, J. Zhang, and Y. Luo, "Numerical simulation and experiment on characteristics of centrifugal pump inlet recirculation," Journal of Drainage and Irrigation Machinery Engineering, vol. 29, no. 6, pp. 461-465, 2011.

[8] K. Zhang, Principle of Fluid Machinery, China Machine Press, Beijing, China, 2010. 

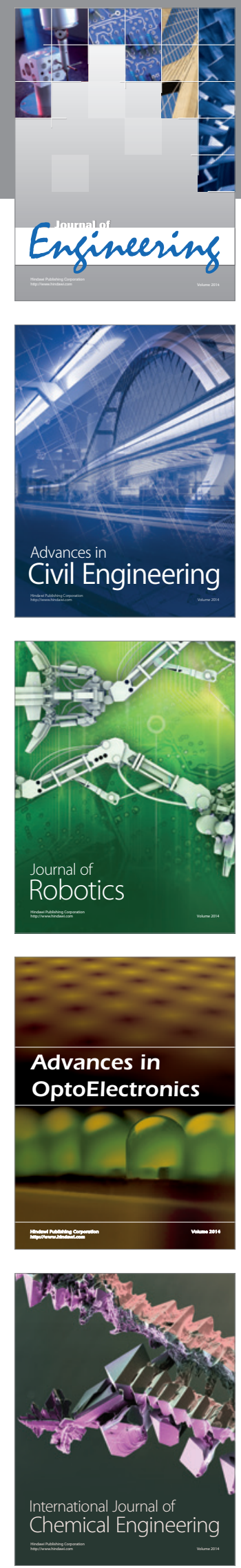

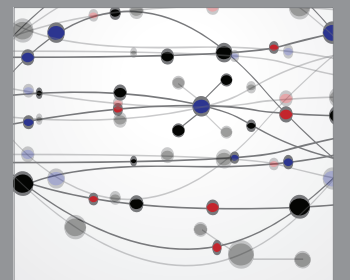

The Scientific World Journal
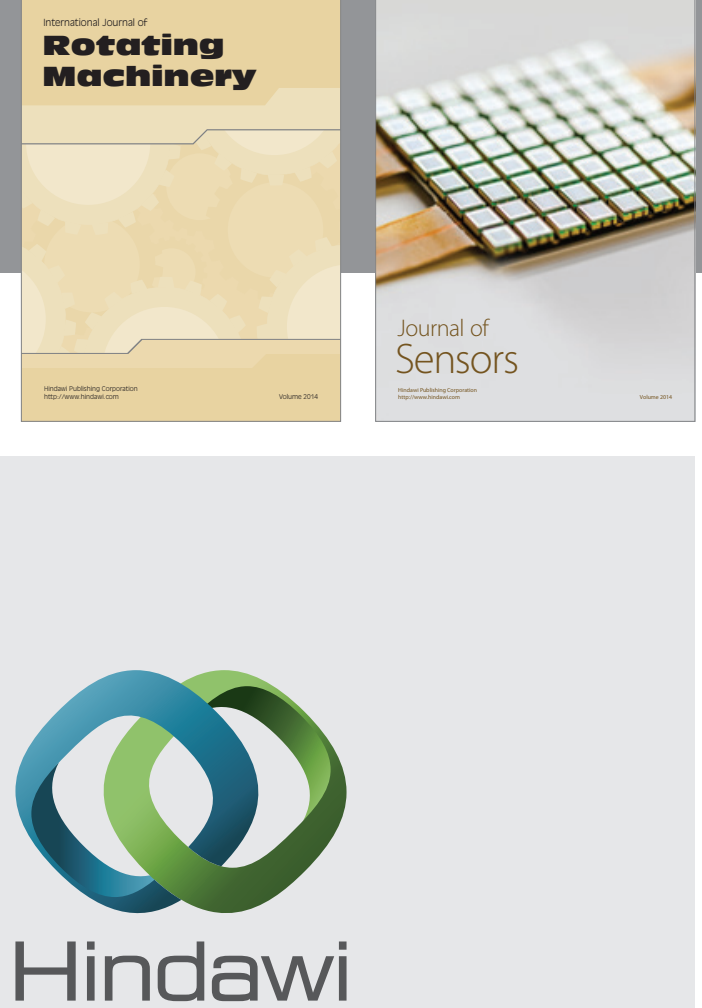

Submit your manuscripts at http://www.hindawi.com
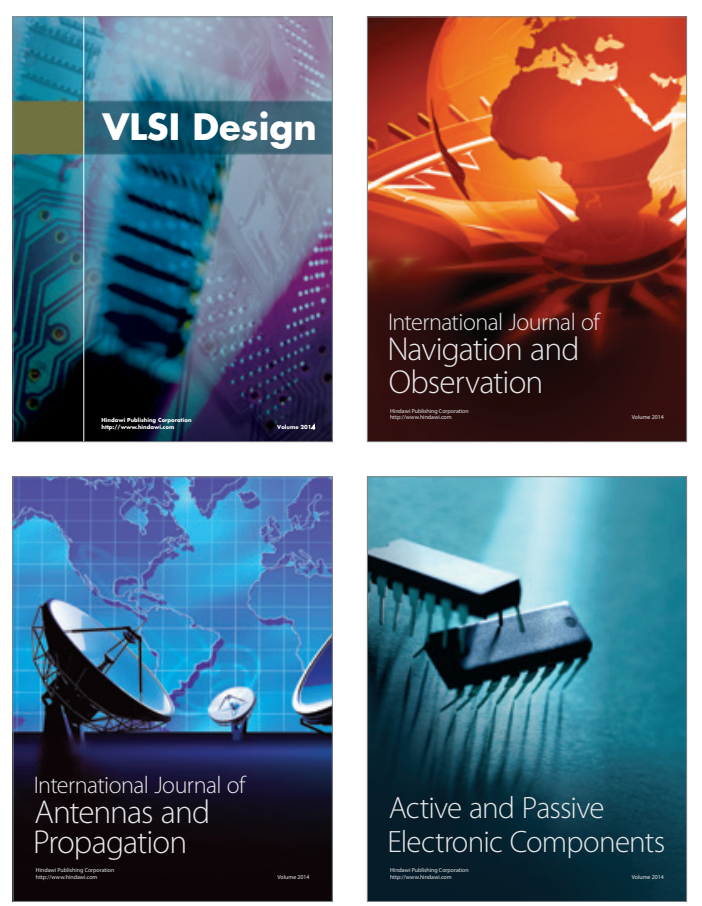
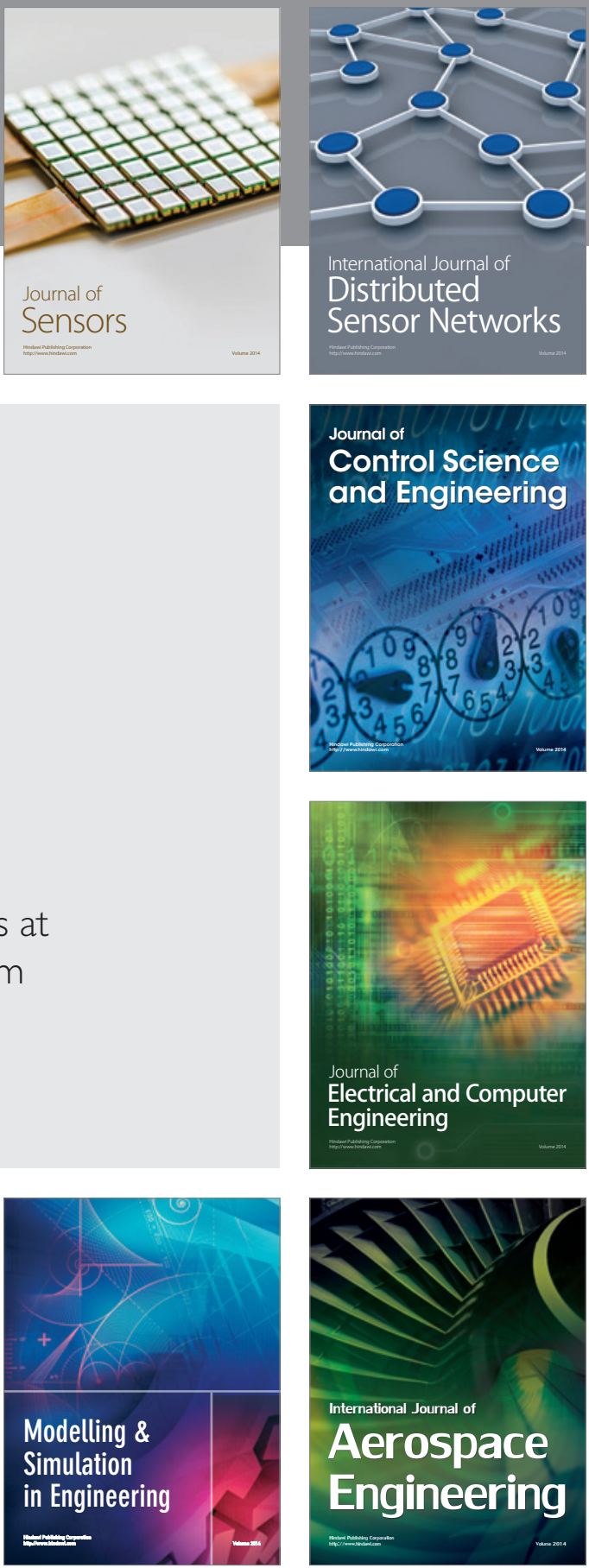

Journal of

Control Science

and Engineering
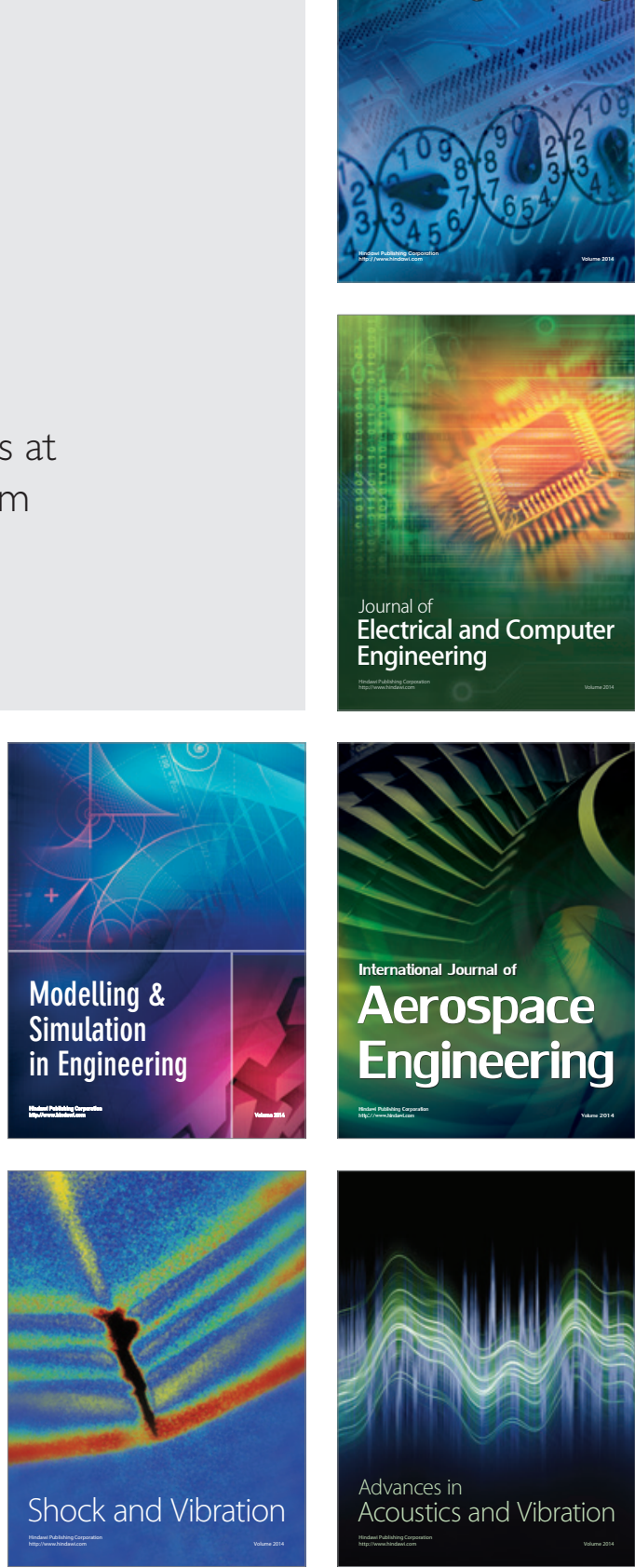